\title{
Phase Behavior and Crystal Structure of Binary Polycyclic Aromatic Compound Mixtures
}

\author{
Jinxia Fu ${ }^{1, *}$, James W. Rice ${ }^{2}$ and Eric M. Suuberg ${ }^{2}$ \\ ${ }^{1}$ Brown University Department of Chemistry, Providence, RI \\ ${ }^{2}$ Brown University School of Engineering, Providence, RI
}

USA

\section{Introduction}

Polycyclic aromatic hydrocarbons (PAHs) are a class of compounds that consist of multiple fused aromatic rings. Concerns have been raised regarding PAHs due to their known health effects(Luthy et al., 1994; Sun et al., 2003). In addition PAHs, chlorinated and brominated polycyclic aromatic hydrocarbons (CIPAHs and BrPAHs) are of interest commercially and of concern for their environmental effects (Shiraishi et al., 1985; Haglund et al., 1987; Nilsson and Ostman, 1993; Koistinen et al., 1994a, b; Ishaq et al., 2003; Kitazawa et al., 2006; Horii et al., 2008; Horii et al., 2009; Ohura et al., 2009; Ni et al., 2010; Ohura et al., 2010). The thermodynamic properties of pure PAHs have been widely studied for more than 50 years (Szczepanik et al., 1963; Wakayama and Inokuchi, 1967; Murray and Pottie, 1974; De Kruif, 1980; Mackay et al., 1982; Bender et al., 1983; Sonnefeld et al., 1983; Hansen and Eckert, 1986; Sato et al., 1986; Hinckley et al., 1990; Nass et al., 1995; Oja and Suuberg, 1997; Ruzicka et al., 1998; Chickos and Acree, 1999; Shiu and Ma, 2000; Burks and Harmon, 2001; Lei et al., 2002; Mackay et al., 2006; Odabasi et al., 2006; Goldfarb and Suuberg, 2008b, a, c; Ma et al., 2010). However, PAHs and halogenated polycyclic aromatic hydrocarbons (HPAHs) often exist as solid and/or liquid mixtures. Therefore it is also important to understand the phase behavior and crystal structures of these PAH and HPAH mixtures.

Phase behavior involving solid-liquid equilibrium is the basis for crystallization in chemical and materials engineering. Binary mixture systems can have up to three degrees of freedom according to the Gibbs phase rule,

$$
\mathrm{F}=\mathrm{C}-\mathrm{P}+2
$$

where $\mathrm{F}$ is the degrees of freedom, $\mathrm{C}$ is the number of components, and $\mathrm{P}$ is the number of phases. Therefore, the equilibrium of binary systems is determined by three variables such as temperature, pressure, and composition, and this is of course increased by one compositional variable for each additional component.

More than half of the true binary organic mixture systems in the literature exhibit simple eutectic behavior (Matsuoka, 1991) (see Figure 1(A)), while about 10\% of binary solid systems form solid solutions (Matsuoka, 1991) (see Figure 1(B)), in which the atoms or molecules of one of the components occupy sites in the crystal lattice of the other component 
without modifying its crystal structure. Additionally, about a quarter of these systems form intermolecular compounds (Matsuoka, 1991), such as monotectics (see Figure 1(C)). However, only limited research has been done on binary organic mixture systems, especially PAH binary mixture systems. Moreover, crystal morphology, i.e., polymorphs, racemates, and structural isomers, also affect the phase diagram and may induce non-ideal solid-liquid equilibrium.

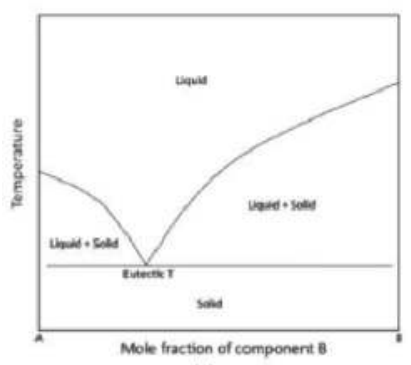

(A)

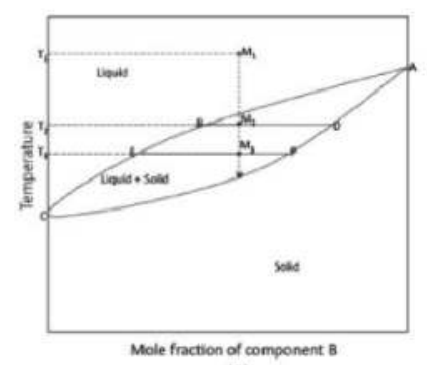

(B)

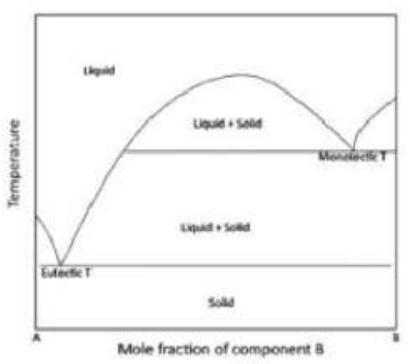

(C)

Fig. 1. Phase diagram of eutectic (A), solid solution (B), and monotectic (C) systems.

\section{Eutectic systems}

Figure 1(A) shows a phase diagram of a typical eutectic mixture system, which has a minimum melting temperature, i.e. a eutectic point. The eutectic point of a binary condensed mixture is defined as the temperature at which a solid mixture phase is in equilibrium with the liquid phase and a eutectic is generally considered to be a simple mechanical mixture of the solid and liquid (Rastogi and Bassi, 1964).

As in many other binary alloy mixtures, most PAH binary mixture systems exhibit eutectic behavior. Table 1 lists the eutectic point and eutectic concentration for about 50 binary PAHcontaining mixture systems, in which at least one of the components is a PAH. The shape of the phase diagram for most of these binary mixture systems is similar to the phase diagram of anthrancene + pyrene mixture system (see Figure 2), except for a few systems, whose eutectic concentration is quite close to a pure component, such as in the naphthalene + chrysene system and phenanthrene + chrysene system.

For the studies preformed by this group on the anthracene + pyrene system (Rice et al., 2010), mixtures were prepared at various compositions by using a melt and quench-cool technique (Fu et al., 2010). Generally, the melting points and enthalpies of fusion of these PAH binary mixtures were found to often actually be independent of mixture preparation techniques. The liquidus and thaw points were determined according to the method proposed by Pounder an Masson (Pounder and Masson, 1934). The thaw temperature is the temperature at which the first droplet of liquid appears in a mixture-containing capillary. The liquidus temperature is the maximum temperature at which both solid crystals and liquid are observed to coexist. Above this temperature, there is only liquid phase present. 


\begin{tabular}{|c|c|c|c|c|}
\hline System & $T_{\text {fus1 }} / \mathrm{K}$ & $T_{\text {fus } 2 / K}$ & $x_{1}$ & $T_{\mathrm{E}} / \mathrm{K}$ \\
\hline $\begin{array}{l}\text { Naphthalene(1) + a-Naphthylamine(2) } \\
\text { (Rastogi and Rama Varma, 1956) }\end{array}$ & 353.5 & 323.2 & 0.360 & 301.3 \\
\hline $\begin{array}{l}\text { Naphthalene(1) + a-Naphthol(2) } \\
\text { (Rastogi and Rama Varma, 1956) }\end{array}$ & 353.5 & 368.2 & 0.487 & 327.7 \\
\hline $\begin{array}{l}\text { Naphthalene(1) + Phenanthrene(2) } \\
\text { (Rastogi and Rama Varma, 1956; } \\
\text { Rastogi and Bassi, 1964) }\end{array}$ & 353.5 & 373.2 & 0.558 & 321.3 \\
\hline $\begin{array}{l}\text { Naphthalene(1) + 2-methylnaphthalene(2) } \\
\text { (Szczepanik et al., 1963) }\end{array}$ & 353.5 & 307.6 & 0.362 & 298.7 \\
\hline $\begin{array}{l}\text { Naphthalene(1) + Thionaphthene(2) } \\
\text { (Szczepanik et al., 1963; Szczepanik } \\
\text { and Ryszard, 1963) }\end{array}$ & 353.5 & 305.2 & 0.063 & 302.4 \\
\hline $\begin{array}{l}\text { Naphthalene(1) + Biphenyl(2) } \\
\text { (Szczepanik et al., 1963; Szczepanik } \\
\text { and Ryszard, 1963) }\end{array}$ & 353.5 & 343.7 & 0.442 & 312.4 \\
\hline $\begin{array}{l}\text { Naphthalene(1) + 2,6- } \\
\text { dimethylnaphthalene(2)(Szczepanik and } \\
\text { Ryszard, 1963) }\end{array}$ & 353.5 & 383.2 & 0.665 & 333.7 \\
\hline $\begin{array}{l}\text { Naphthalene }(1)+2,3- \\
\text { dimethylnaphthalene(2)(Szczepanik and } \\
\text { Ryszard, 1963) }\end{array}$ & 353.5 & 377.2 & 0.666 & 327.4 \\
\hline $\begin{array}{l}\text { Naphthalene(1) + Acenaphthene }(2) \\
\text { (Szczepanik et al., 1963; Szczepanik } \\
\text { and Ryszard, 1963) }\end{array}$ & 353.5 & 368.5 & 0.564 & 324.6 \\
\hline $\begin{array}{l}\text { Naphthalene(1) + Fluorene(2) } \\
\text { (Szczepanik et al., 1963; Szczepanik } \\
\text { and Ryszard, 1963) }\end{array}$ & 353.5 & 388.2 & 0.613 & 330.2 \\
\hline $\begin{array}{l}\text { Naphthalene(1) + Phenanthrene (2) } \\
\text { (Szczepanik et al., 1963; Szczepanik } \\
\text { and Ryszard, 1963) }\end{array}$ & 353.5 & 373.2 & 0.552 & 323.2 \\
\hline $\begin{array}{l}\text { Naphthalene(1) + Fluoranthene (2) } \\
\text { (Szczepanik et al., 1963; Szczepanik } \\
\text { and Ryszard, 1963) }\end{array}$ & 353.5 & 383.2 & 0.612 & 331 \\
\hline $\begin{array}{l}\text { Naphthalene(1) + Pyrene (2) } \\
\text { (Szczepanik et al., 1963; Szczepanik } \\
\text { and Ryszard, 1963) }\end{array}$ & 353.5 & 423.2 & 0.746 & 339.2 \\
\hline $\begin{array}{l}\text { Naphthalene(1) + Chrysene(2) } \\
\text { (Szczepanik et al., 1963; Szczepanik } \\
\text { and Ryszard, 1963) }\end{array}$ & 353.5 & 528.2 & 0.971 & 351.4 \\
\hline $\begin{array}{l}\text { Biphenyl(1) + Fluorene(2) } \\
\text { (Szczepanik et al., 1963; Szczepanik } \\
\text { and Ryszard, 1963) }\end{array}$ & 343.7 & 388.2 & 0.909 & 340.8 \\
\hline $\begin{array}{l}\text { Biphenyl(1) + Acenaphthene(2) } \\
\text { (Szczepanik et al., 1963; } \\
\text { Szczepanik and Ryszard, 1963) }\end{array}$ & 343.7 & 368.5 & 0.641 & 319.3 \\
\hline
\end{tabular}


Diphenylene oxide(1) + Acenaphthene(2)

(Szczepanik et al., 1963; Szczepanik

and Ryszard, 1963)

Fluorene(1) + Acenaphthene(2)

(Szczepanik et al., 1963; Szczepanik

and Ryszard, 1963)

Fluorene(1) + 2,3,6-trimethylnaphthalene(2)

(Szczepanik et al., 1963; Szczepanik

and Ryszard, 1963)

Phenanthrene(1) + Biphenyl(2)

(Szczepanik et al., 1963; Szczepanik

and Ryszard, 1963)

Phenanthrene(1) + Acenaphthene(2)

(Szczepanik et al., 1963; Szczepanik

and Ryszard, 1963)

Phenanthrene(1) + 2,3,6-trimethylnaphthalene(2)

(Szczepanik et al., 1963; Szczepanik

and Ryszard, 1963)

Phenanthrene(1) + Fluorene(2)

(Szczepanik et al., 1963; Szczepanik

and Ryszard, 1963)

Phenanthrene(1) + Pyrene(2)

(Szczepanik et al., 1963; Szczepanik

and Ryszard, 1963)

Phenanthrene(1) + 3-methylphenanthrene(2)

(Szczepanik et al., 1963; Szczepanik

and Ryszard, 1963)

Phenanthrene(1) + 4,5-dimethylphenanthrene(2)

(Szczepanik et al., 1963; Szczepanik

and Ryszard, 1963)

Phenanthrene(1) + Fluoranthene (2)

(Szczepanik et al., 1963; Szczepanik

and Ryszard, 1963)

Phenanthrene(1) + Chrysene(2)

(Szczepanik et al., 1963; Szczepanik

and Ryszard, 1963)

Anthracene(1) + Carbazole(2)

(Szczepanik et al., 1963; Szczepanik

and Ryszard, 1963)

Anthracene(1) + 2-methylanthracene(2)

(Szczepanik et al., 1963; Szczepanik

and Ryszard, 1963)

Anthracene(1) + Chrysene(2)

(Szczepanik et al., 1963; Szczepanik

and Ryszard, 1963) $\begin{array}{llll}359.2 & 368.5 & 0.578 & 326\end{array}$

$\begin{array}{llll}388.2 & 368.5 & 0.431 & 338.6\end{array}$

$\begin{array}{llll}388.2 & 375.2 & 0.658 & 361.6\end{array}$

$\begin{array}{llll}373.2 & 343.7 & 0.691 & 324.8\end{array}$

$\begin{array}{llll}373.2 & 368.5 & 0.495 & 327.5\end{array}$

$\begin{array}{llll}373.2 & 375.2 & 0.704 & 331.5\end{array}$

$\begin{array}{llll}373.2 & 388.2 & 0.637 & 368.7\end{array}$

$\begin{array}{llll}373.2 & 423.2 & 0.747 & 354.7\end{array}$

$\begin{array}{llll}373.2 & 332 & 0.318 & 309.7\end{array}$

$\begin{array}{llll}373.2 & 388.2 & 0.621 & 342.6\end{array}$

$\begin{array}{llll}373.2 & 383.2 & 0.532 & 347.7\end{array}$

$\begin{array}{llll}373.2 & 528.2 & 0.957 & 369.2\end{array}$

$\begin{array}{llll}489.8 & 518 & 0.943 & 488.4\end{array}$

$\begin{array}{llll}489.8 & 472.2 & 0.108 & 471.5\end{array}$

$\begin{array}{llll}489.8 & 528.2 & 0.662 & 464.6\end{array}$ 
Anthracene(1) + Pyrene(2)

(Szczepanik et al., 1963; Szczepanik and Ryszard, 1963)

Carbazole(1) + Fluoranthene(2)

(Szczepanik et al., 1963; Szczepanik and Ryszard, 1963)

Carbazole(1) + Pyrene(2)

(Szczepanik et al., 1963; Szczepanik and Ryszard, 1963)

Carbazole(1) + Chrysene(2)

(Szczepanik et al., 1963; Szczepanik and Ryszard, 1963)

Fluoranthene(1) + Acenaphthene(2)

(Szczepanik et al., 1963; Szczepanik and Ryszard, 1963)

Fluoranthene(1) + Fluorene(2)

(Szczepanik et al., 1963; Szczepanik and Ryszard, 1963)

Fluoranthene(1) + 2-methylanthracene (2)

(Szczepanik et al., 1963; Szczepanik

and Ryszard, 1963)

Fluoranthene(1) + Pyrene(2)

(Szczepanik et al., 1963; Szczepanik

and Ryszard, 1963)

Fluoranthene(1) + Chrysene(2)

(Szczepanik et al., 1963; Szczepanik

and Ryszard, 1963)

Pyrene(1) + Chrysene(2)

(Szczepanik et al., 1963; Szczepanik

and Ryszard, 1963)

Acenaphthene (1) + 1,2-dimethylbenzene(2)

(Szczepanik et al., 1963; Szczepanik

and Ryszard, 1963)

Acenaphthene (1) + 1,2,4,5-tetramethylbenzene(2)

(Szczepanik et al., 1963; Szczepanik

and Ryszard, 1963)

Acenaphthene (1) + 2-methylnaphthalene(2)

(Szczepanik et al., 1963; Szczepanik

and Ryszard, 1963)

Acenaphthene (1) + 2,6-dimethylnaphthalene (2)

(Szczepanik et al., 1963; Szczepanik

and Ryszard, 1963)

Acenaphthene (1) + 2,7-dimethylnaphthalene (2)

(Szczepanik et al., 1963; Szczepanik

and Ryszard, 1963) $\begin{array}{llll}489.8 & 423.2 & 0.221 & 404.6\end{array}$

$\begin{array}{llll}518 & 383.2 & 0.119 & 377.3\end{array}$

$\begin{array}{llll}518 & 423.2 & 0.154 & 409.1\end{array}$

$\begin{array}{llll}518 & 528.2 \quad 0.578 \quad 480.6\end{array}$

$\begin{array}{llll}383.2 & 368.5 & 0.433 & 336.9\end{array}$

$\begin{array}{llll}383.2 & 388.2 & 0.516 & 342.7\end{array}$

$\begin{array}{llll}383.2 & 472.2 & 0.794 & 368.7\end{array}$

$\begin{array}{llll}383.2 & 423.2 & 0.800 & 368.3\end{array}$

$\begin{array}{lll}383.2 & 528.2 \quad 0.952 \quad 379.6\end{array}$

$\begin{array}{llll}423.2 & 528.2 & 0.855 & 405.7\end{array}$

$\begin{array}{llll}368.5 & 298.7 & 0.055 & 295\end{array}$

$\begin{array}{llll}368.5 & 352.3 & 0.423 & 323.6\end{array}$

$\begin{array}{llll}368.5 & 307.5 & 0.212 & 290.9\end{array}$

$\begin{array}{llll}368.5 & 383.2 & 0.598 & 339.7\end{array}$

$\begin{array}{llll}368.5 & 370.2 & 0.531 & 333.9\end{array}$ 
Acenaphthene (1) + Naphthalene (2)

$\begin{array}{llll}368.5 & 353.2 & 0.417 & 323.2\end{array}$

(Szczepanik et al., 1963; Szczepanik

and Ryszard, 1963)

Acenaphthene (1) + Phenanthrene(2)

368.5

(Szczepanik et al., 1963; Szczepanik

and Ryszard, 1963)

Acenaphthene (1) + Fluorene(2)

(Szczepanik et al., 1963; Szczepanik

$\begin{array}{llll}368.5 & 387.2 & 0.582 & 337.7\end{array}$

and Ryszard, 1963)

Acenaphthene (1) + Anthracene(2)

(Szczepanik et al., 1963; Szczepanik

and Ryszard, 1963)

Table 1. Melting temperatures of previously reported binary PAH eutectic systems

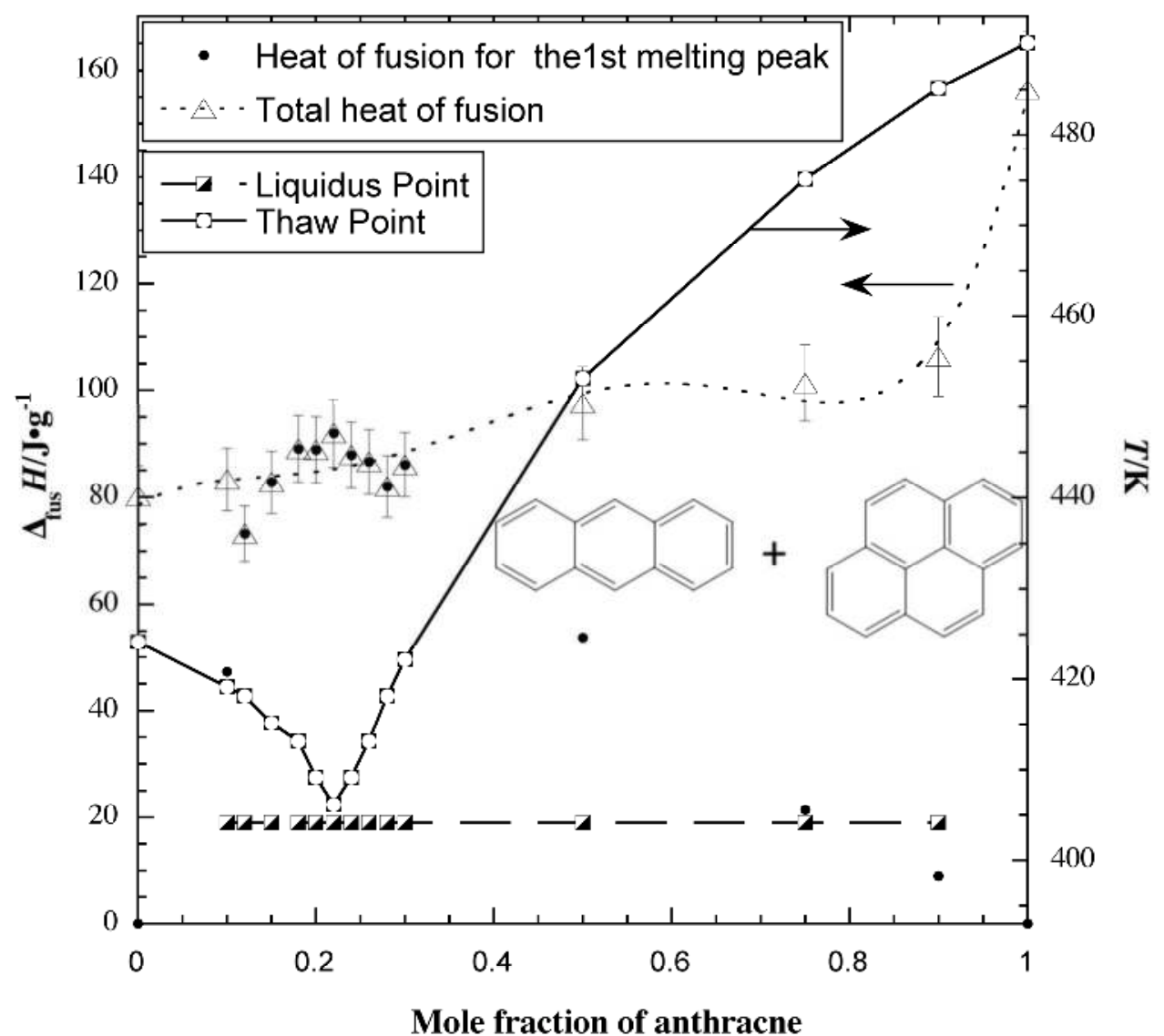

Fig. 2. Phase diagram and enthalpy of fusion of the anthracene (1) + pyrene (2) system (Rice et al., 2010). 
The eutectic point for the anthracene (1) + pyrene (2) system occurs at $404 \mathrm{~K}$ at $x_{1}=0.22$ (see Figure 2). Only solid state exists below the thaw curve, i.e. eutectic temperature, and only liquid state exists above the liquidus curve. The areas between these two curves exhibit the coexistence of both solid and liquid phases.

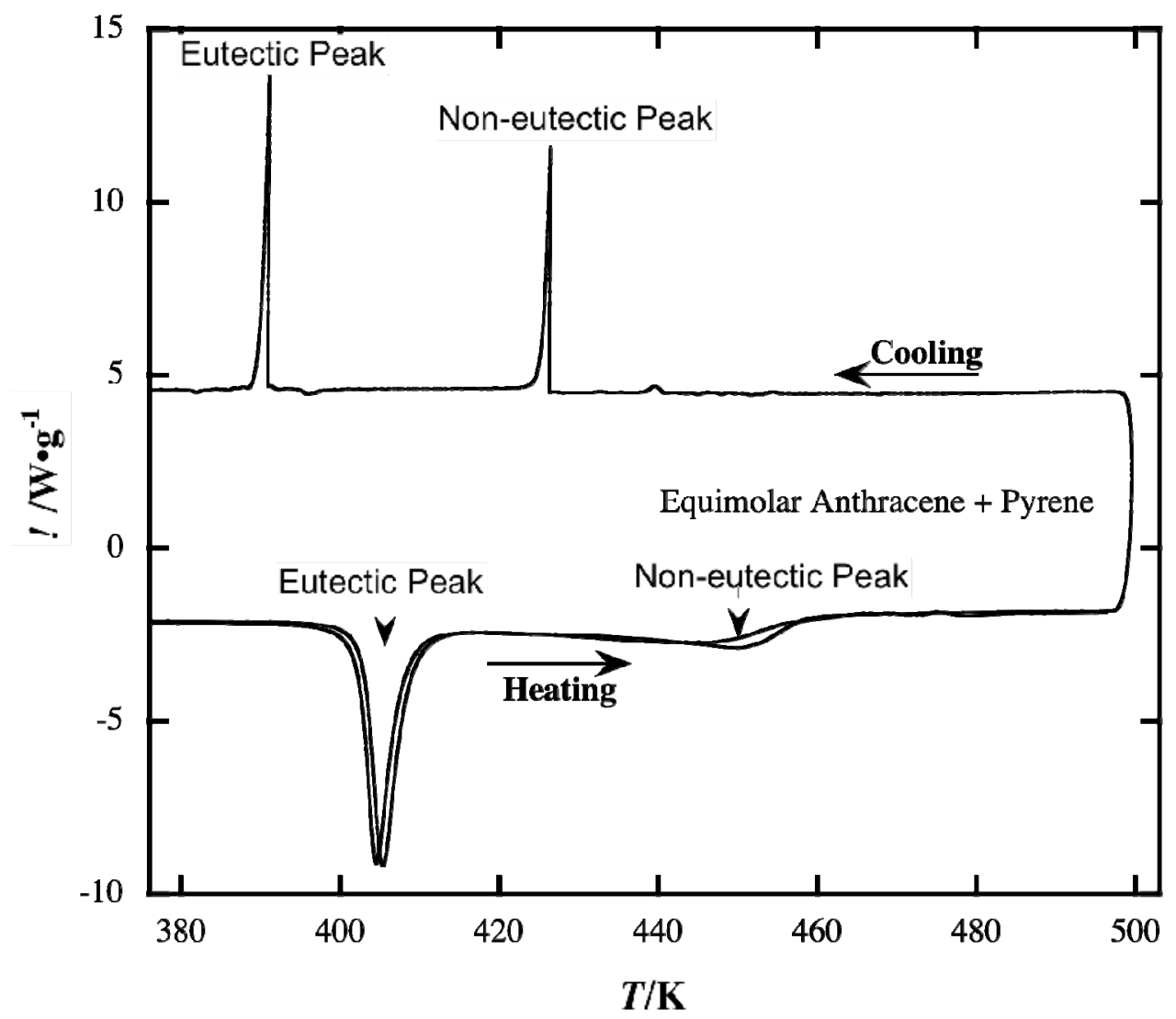

Fig. 3. Full DSC scan of an equimolar anthracene (1) + pyrene (2) mixture (Rice et al., 2010).

Figure 2 also displays the correlation between phase behavior and enthalpy of fusion, $\Delta_{\text {fus }} H$ for the system. The $\Delta_{\text {fus }} H$ observed for a DSC peak near the eutectic temperature of $404 \mathrm{~K}$ indicates the heat input for the initial melting of a eutectic solid phase to occur. The total $\Delta_{\text {fus }} H$ shown in Figure 2 is a summation of both endothermic phase transition peaks observed in the DSC scan, i.e. the eutectic phase melting and the non-eutectic phase melting (see Figure 3). It is worth noting that the total $\Delta_{\text {fus }} H$ is very similar to that of pure pyrene over a wide range of compositions and thus the $\Delta_{\text {fus }} H$ for both pure pyrene and the eutectic mixture are very similar. This means that when the mixture contains only a modest amount of anthracene, energetically it behaves quite similarly to pure pyrene, and this persists until the mixture is nearly pure anthracene (see Figure 2). There is a slight increase in fusion enthalpy when the mixtures are enriched in anthracene beyond the eutectic composition, 
but the shift is only modest as compared with the increase of fusion enthalpy to that of pure anthracene (see Figure 2). This indicates that the ability of anthracene to reach a lower energy crystalline configuration is significantly impeded by the presence of relatively small amounts of pyrene.

Additionally, Powder X-ray diffraction patterns for the same anthracene (1) + pyrene (2) system were also obtained. Figure 4 shows that the crystal structure of the eutectic mixture is similar to that of pyrene because peaks at 10.6, 11.6, 14.9, 16.3, 18.2, 23.3, 24.7 and 28.0 degree are all retained in the mixture diffraction pattern. This is consistent with the DSC result that implies that the $\Delta_{\text {fus }} H$ of the eutectic is very close to that of pure pyrene, and indicates that the crystal structures of the eutectic mixture and pure pyrene are similar. Likewise, Figure 4 shows that the crystal structure of a mixture at $x_{1}=0.90$ is comparable to that of pure anthracene.

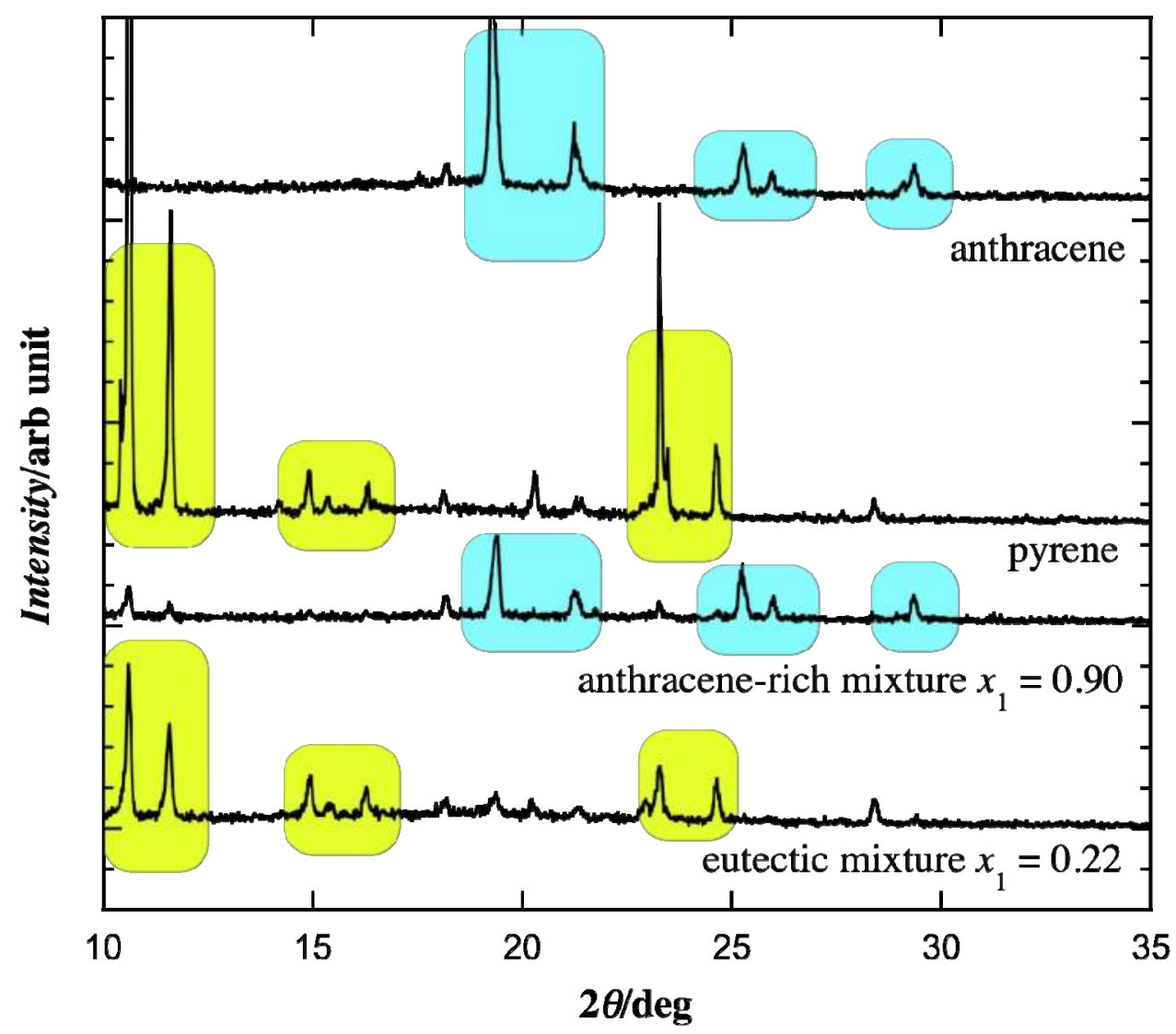

Fig. 4. X-ray diffraction patters of pure components and mixtures of anthracene (1) + pyrene (2) (Rice et al., 2010). 


\section{Monotectic systems}

In contrast to eutectic systems, in which both components solidify below eutectic temperature, a monotectic reaction is characterized by the breakdown of a liquid into one solid and one liquid phase (Singh et al., 1985), i.e. one liquid phase decomposes into a solid phase and a liquid phase when the temperature is below the monotectic temperature. Figure $1(\mathrm{C})$ shows the phase diagram of a typical monotectic system. The monotectic composition is determined by the intersection of a liquidus line and a liquid miscibility gap (Singh et al., 1985). Generally, monotectic systems are less studied than eutectic systems.

Binary organic mixtures with PAHs can form monotectic systems. Table 2 lists the monotectic and eutectic point of a few monotectic forming PAH systems. Monotectic systems are characterized by monotectic, eutectic and upper consolute temperatures, though the upper consolute temperature is often not reported. The monotectic temperature, $t_{\mathrm{M}}$, is the temperature at monotectic composition and the upper consolute temperature is the highest melting temperature of the mixture system, i.e. the critical point where the two liquid phases having identical composition become indistinguishable.

\begin{tabular}{|c|c|c|c|c|c|c|}
\hline System & $T_{\text {fus1 }} / \mathrm{K}$ & $T_{\text {fus } 2 / K}$ & $x_{M}$ & $T_{\mathrm{M}} / \mathrm{K}$ & $x_{\mathrm{E}}$ & $T_{\mathrm{E}} / \mathrm{K}$ \\
\hline $\begin{array}{l}\text { 2,4-Dinitrophenol(1) + } \\
\text { Naphthalene(2) } \\
\text { (Singh et al., 2001: Singh et al., 2007) }\end{array}$ & 378.2 & 353.2 & 0.316 & 357.7 & 0.838 & 344.2 \\
\hline $\begin{array}{l}\text { Succinonitrile (1) + Pyrene(2) } \\
\text { (Rai and Pandey, 2002) }\end{array}$ & 330.2 & 423.2 & 0.025 & 416.5 & 0.744 & 328.5 \\
\hline $\begin{array}{l}\text { Succinonitrile (1) + Phenanthrene (2) } \\
\text { (Singh et al., 1985) }\end{array}$ & 330.2 & 373.2 & 0.225 & $363.2^{a}$ & 0.975 & $\sim 328.2$ \\
\hline $\begin{array}{l}\text { p-benzoquinone }(1)+\text { Pyrene }(2) \\
\text { (Gupta and Singh, 2004) }\end{array}$ & 388.2 & 423.2 & 0.324 & 392.2 & 0.792 & 376.2 \\
\hline $\begin{array}{l}\text { m-dinitrobenzene(1)+ Pyrene(2) } \\
\text { (Gupta and Singh, 2004) }\end{array}$ & 362.2 & 423.2 & 0.301 & 363.2 & 0.702 & 361.2 \\
\hline $\begin{array}{l}\text { m-nitrobenzoic acid(1) +Pyrene(2) } \\
\text { (Gupta and Singh, 2004) }\end{array}$ & 413.2 & 423.2 & 0.902 & 413.2 & 0.299 & 403.2 \\
\hline
\end{tabular}

Table 2. Melting temperatures of previously reported binary PAH monotectic systems

Rai and Pandey studied the phase behavior of succinonitrile (1) + pyrene (2) mixture system (Rai and Pandey, 2002), which is a typical monotectic system (Figure 5). The enthalpy of fusion of pyrene, $17.65 \mathrm{~kJ} \mathrm{~mole}^{-1}$ (Chickos and Acree, 1999), is much higher than that of succinonitrile, $3.7 \mathrm{~kJ}$ mole$^{-1}$ (Rai and Pandey, 2002). The monotectic point is $416.5 \mathrm{~K}$ $\left(143.3^{\circ} \mathrm{C}\right)$ at $x_{1}=0.025$. The eutectic temperature is $328.5 \mathrm{~K}\left(55.4^{\circ} \mathrm{C}\right)$ at $x_{1}=0.744$ and the upper consolute temperature, $\mathrm{t}_{\mathrm{C}}\left(465.2 \mathrm{~K}, 192.0^{\circ} \mathrm{C}\right)$, is $48.7 \mathrm{~K}$ above the monotectic point. When $x_{1}$ is between monotectic and eutectic composition, the two liquids, $\mathrm{L}_{1}$ (rich in pyrene) and $\mathrm{L}_{2}$ (rich in succinonitrile) are mutually immiscible. However, if the temperature is above the consolute temperature, there is complete miscibility in liquid state, i.e. only one liquid phase exists. 


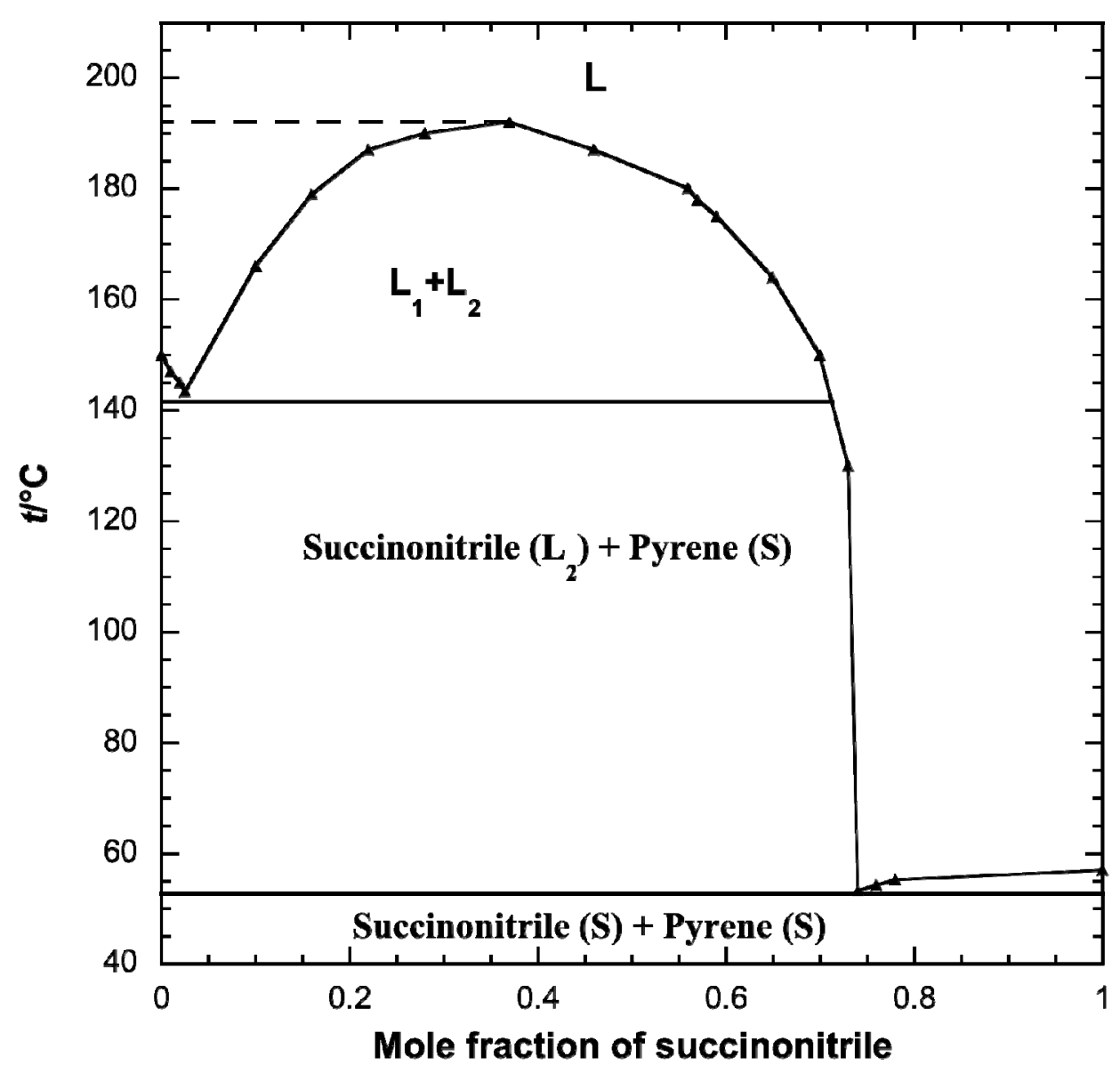

Fig. 5. Phase diagram of succinonitrile (1) + pyrene (2) mixture system (Rai and Pandey, 2002).

\section{Solid solution}

A solid solution is a solid mixture in which one or more atoms and/or molecules of one of the components occupies sites in the crystal lattice of the other component without significantly changing its crystal structure, even though the lattice parameter may vary. So this kind of system has a homogenous crystalline structure and is also called isomorphic system, because the components are completely miscible in both the liquid and solid phases. Figure 1(B) shows the phase behavior of a binary mixture system that forms a solid solution. In the diagram, the curve $A B C$ and $A D C$ are the liquidus and solidus curves, respectively. The area above $\mathrm{ABC}$ curve represents the region of homogeneous liquid solutions and the area below ADC curve represents the region of homogeneous solid solution. The area enclosed by ABCD is the region of liquid + solid solution. For instance, a mixture $\mathrm{M}_{1}$ at temperature $T_{1}$ is cooled to temperature $T_{2}$, the 
mixture $M_{2}$ becomes a mixture of liquid $B$ and solid $D$. If $M_{2}$ is further cooled to temperature $T_{3}$, the liquid composition changes continuously from $B$ to $E$ along the liquidus curve, while the solid composition changes from $\mathrm{D}$ to $\mathrm{F}$ along the solidus curve. Additionally, the Hume-Rothery rules, named after William Hume-Rothery, are used to describe the conditions under which an element can dissolve in a metal and form a solid solution.

Szczepanik and Skalmowski (Szczepanik et al., 1963; Szczepanik and Ryszard, 1963) studied the phase behavior of over $60 \mathrm{PAH}$ binary mixture systems, and demonstrate that PAH mixture systems also form solid solution, as shown by naphthalene + 1-methynaphthanlene, naphthalene + anthracene, phenanthrene + anthracene, phenanthrene + carbazole, anthracene + acridine, anthracene + fluoranthene, and chrysene +1 ,2-benzanthracene systems. It is not known whether the the Hume-Rothery rules still work for PAH mixtures. However, it is worth noting that the number of such systems is small, compared with the number of eutectic-forming systems.

\section{Systems with complex phase behavior}

Due to the large molecular mass and complexity of the crystal structure of PAHs, i.e. polymorphism and racemate, the phase behavior of some of the PAH binary mixtures may be different from the above described three phase behaviors. Three complicated PAH binary mixture systems, i.e. anthracene + benzo[a]pyrene system (Rice and Suuberg, 2010), pyrene + 9,10-dibromoanthracene system (Fu et al., 2010), and anthracene + 2-bromoanthracene are introduced here.

\subsection{Anthracene + benzo[a]pyrene system}

Benzo[a]pyrene has a much larger molecular mass compared to pyrene, which leads to phase behavior in the anthracene (1) + benzo[a]pyrene (2) system (Rice and Suuberg, 2010) that is different from that of the anthracene + pyrene system. The phase diagram of anthracene (1) + benzo[a]pyrene (2) system ( see Figure 6) indicates an eutectic-like mixture behavior. A eutectic-like phase is formed near $x_{1}=0.26$ between 414 and $420 \mathrm{~K}$. There is however always a gap between the thaw curve and the lowest liquidus temperature, which is distinct from true eutectic behavior such as in Figure 1(A) or Figure 2. Therefore, mixtures of anthracene and benzo[a]pyrene form a single, amorphous, solid eutectic-like phase at $x_{1}=0.26$ that lacks any organized crystal structure and which melts throughout the 414 to $420 \mathrm{~K}$ temperature range. This region of phase transition, represented by the shaded region of Figure 6, is not rate dependant and is observed in both the DSC and melting temperature analysis for all combinations of anthracene + benzo[a]pyrene, providing evidence that this region represents the melting temperature range of a single, amorphous, solid phase. This conclusion is also supported by the X-ray diffraction results.

Powder X-ray diffraction studies were conducted to study the crystal structures of the anthracene (1) + benzo[a]pyrene (2) system (see Figure 7). The eutectic-like mixture lacks any organized crystal structure because the few peaks that exist in the X-ray pattern are not well defined and do not rise much above the baseline. Additionally, there is no real 
similarity between the eutectic mixture scan and those of the pure components. This result is consistent with the melting point studies that imply that the mixtures form a single, amorphous solid phase at the eutectic composition.

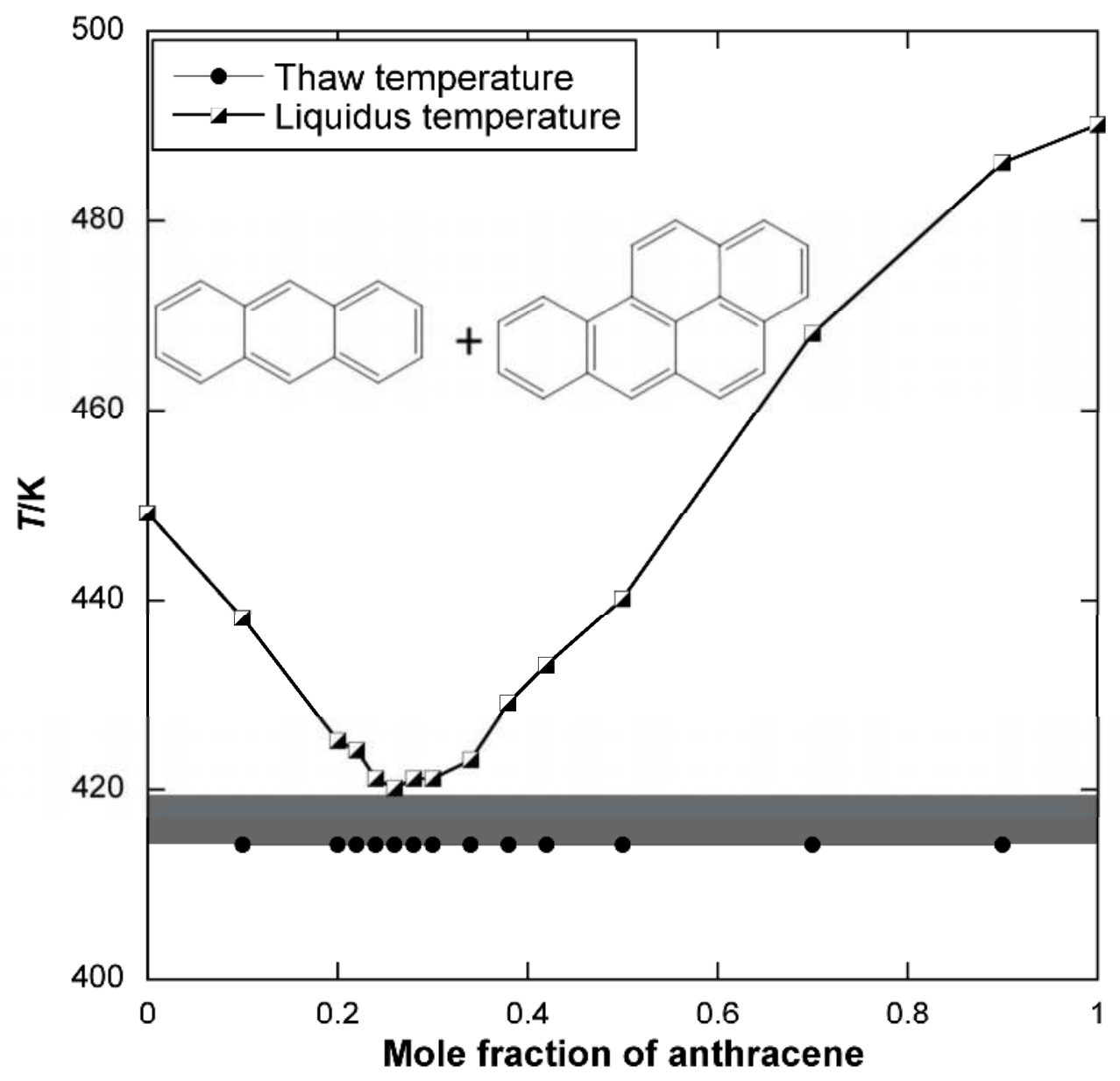

Fig. 6. Phase diagram of anthracene (1) + benzo[a]pyrene (2) system (Rice and Suuberg, 2010). 


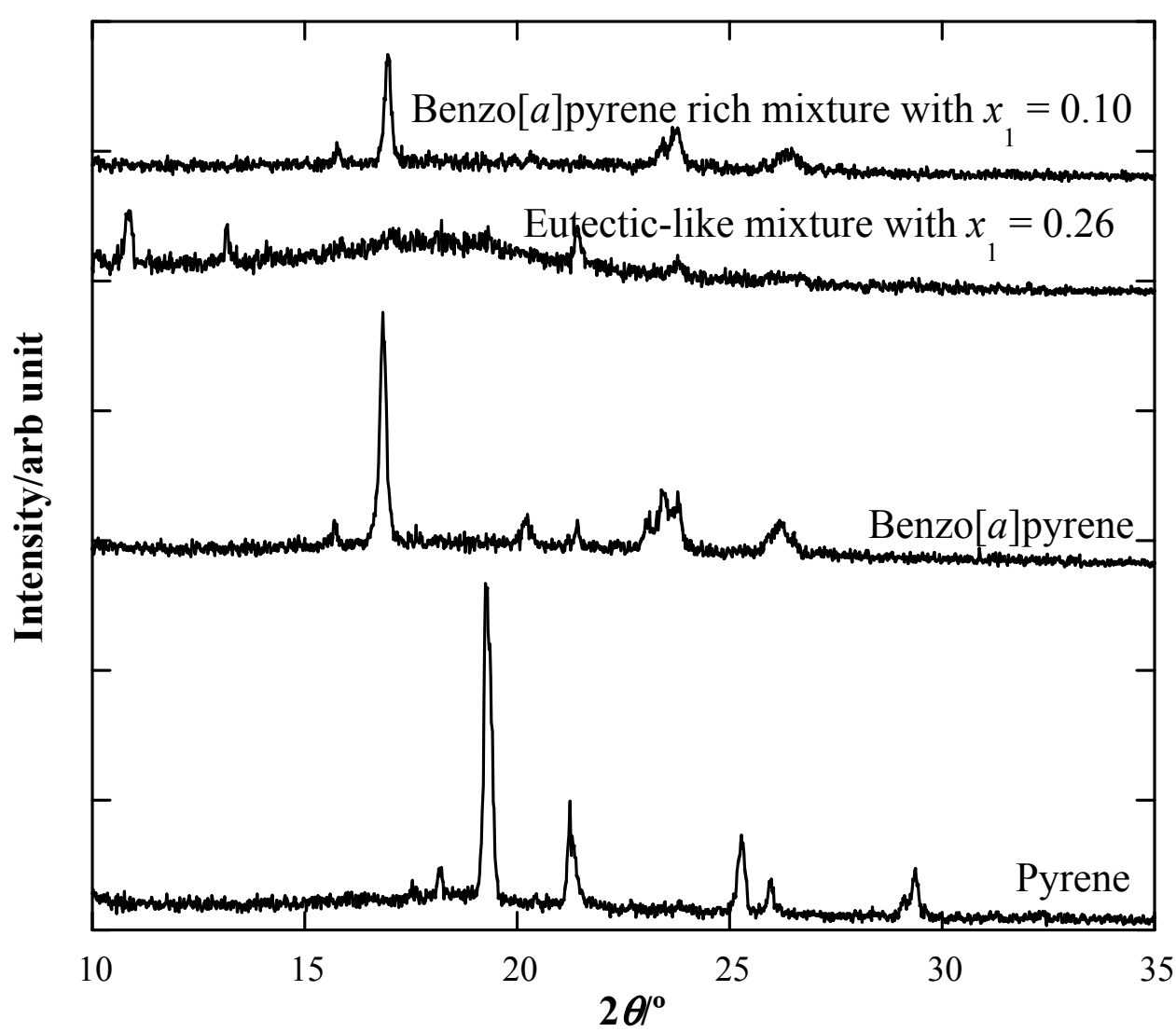

Fig. 7. X-ray diffraction patters of pure components and mixtures of anthracene (1) + benzo[a]pyrene (2) system (Rice and Suuberg, 2010).

\subsection{Pyrene + 9,10-dibromoanthracene system}

The influence of halogen substitution on the interaction energy between PAH molecules has also been investigated. Unlike the anthracene + pyrene mixture system, bromine substitution on anthracene induces a different kind of interaction in the pyrene (1) + 9,10dibromoanthracene (2) mixture system, which also results in non-idealities in solid-liquid equilibrium (see Figure 8). The surface area and volume of the 9,10-dibromoanthracene molecule is much larger than that of pyrene. 


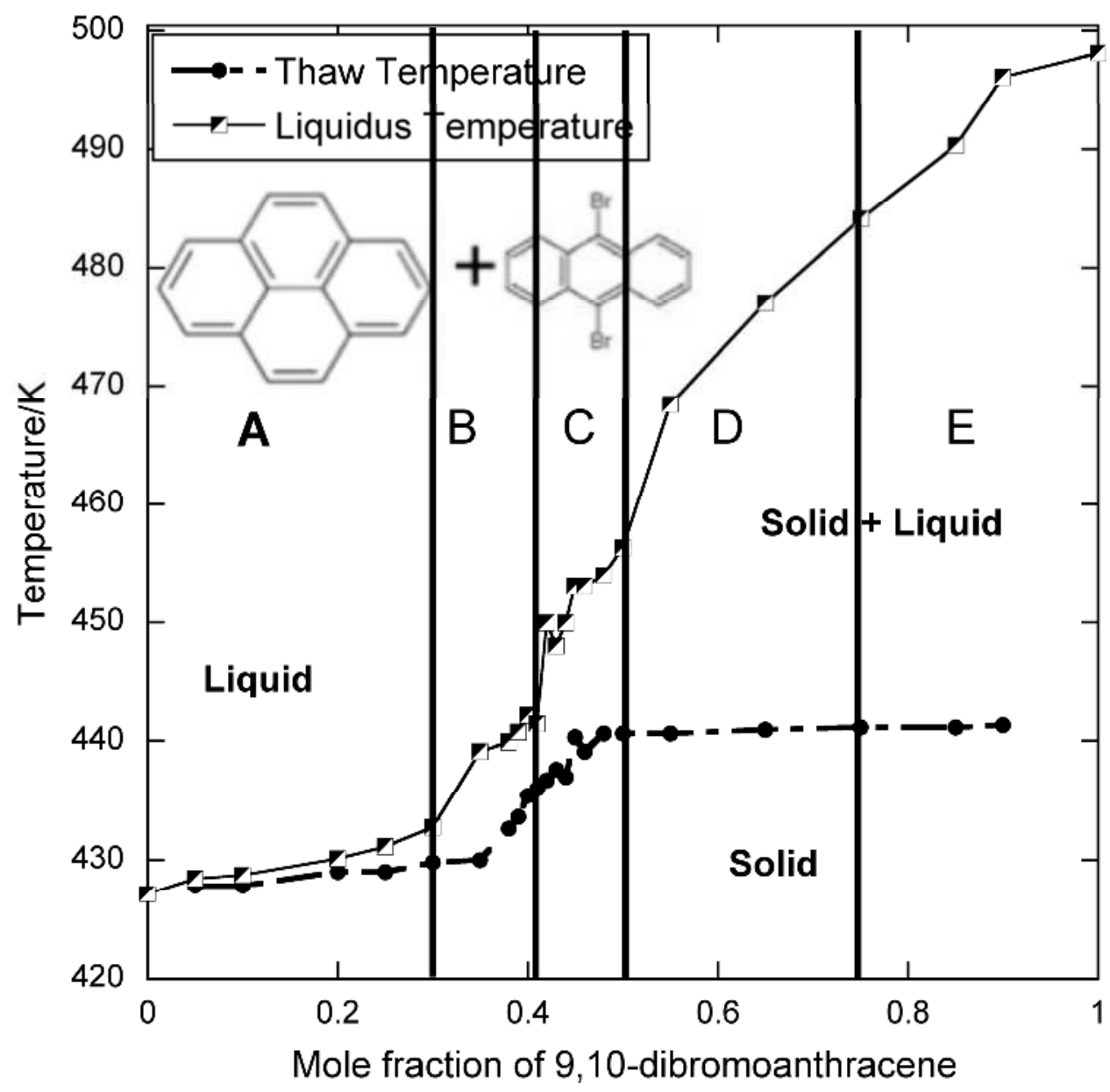

Fig. 8. Phase diagram of pyrene (1) +9,10-dibromoanthracene (2) mixture system (Fu et al., 2010).

The phase diagram of this system can be crudely divided into 5 regions. The mixtures with relatively low mole fraction of 9,10-dibromoanthracene $(<0.30)$, in region A, form a pyrene like phase. When the mole fraction of 9,10-dibromoanthracene is between 0.30-0.41, in region $\mathrm{B}$, the mixtures transition from a pyrene-like phase to two phases that both have low melting temperatures. The divergence of the liquidus and thaw curve is $2-9 \mathrm{~K}$. In region $\mathrm{C}$, mixtures containing about $x_{2}=0.41-0.50$ also show two-phase character and start to transition to 9,10-dibromoanthracene behavior. Mixtures with $x_{2}=0.50-0.75$, in region $\mathrm{D}$, also have two phases with 9,10-dibromoanthracene like behavior and high melting temperature. Only one of the phases evolves while the other gives a constant low melting temperature (corresponding to the thaw point). In region E, a 9,10-dibromoanthracene like phase is defined based upon the thermal behavior, shown below. 
The full heating, cooling and reheating scan of a pyrene $+9,10$-dibromoanthracene mixture at $x_{2}=0.48$ (in region C) is shown in Figure 9, where $\Phi$ is heat flow in the DSC. During the heating scan, two peaks appear at $428 \mathrm{~K}$ and $440 \mathrm{~K}$, which indicates the two-phase character of the mixture. Two peaks are also observed in the cooling scan, in which the 9,10dibromoanthracene like phase crystallizes first at $418 \mathrm{~K}$, and then the pyrene like phase crystallizes at $410 \mathrm{~K}$. The cooling scan also suggested two-phase behavior of the mixture just as did the melting behavior. When reheated, the phase transition enthalpies and associated temperatures matched those of the initial heating scan.

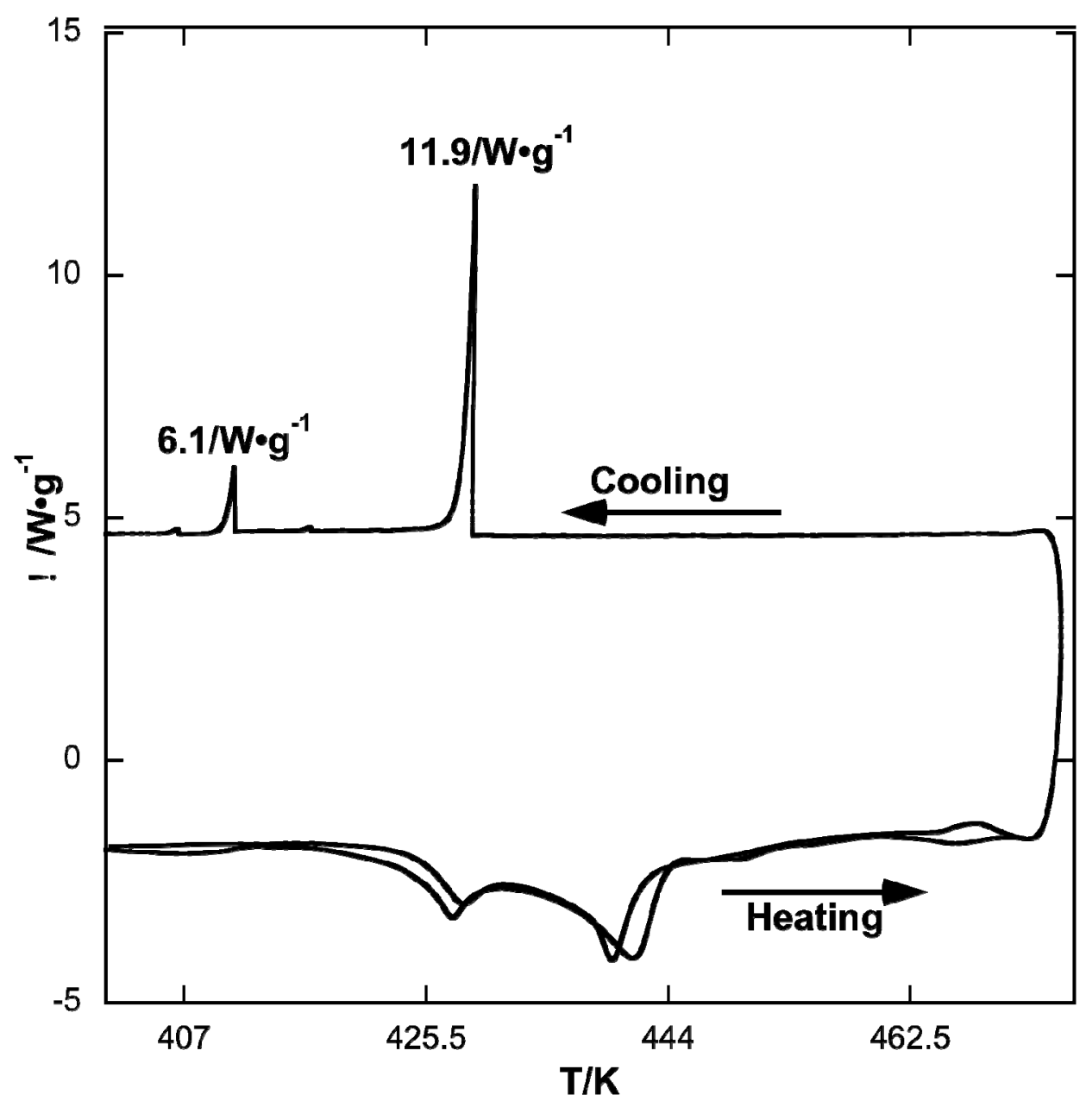

Fig. 9. Full DSC scan of a pyrene (1) $+9,10$-dibromoanthracene (2) mixture at $x_{2}=0.48$ (Fu et al., 2010). 
The temperature and enthalpy of crystallization (subcooled), shown in Figure 10, correspond to the results obtained from the phase diagram. Mixtures with a mole fraction of 9,10-dibromoanthraene $0.30-0.75$, in regions $\mathrm{B}, \mathrm{C}$ and $\mathrm{D}$, have two-phase character, which is observed as two distinct phase-transition peaks during the cooling procedure. Region $\mathrm{E}$ showed two-phase melting behavior, but in the DSC experiments of Figure 10, the low temperature crystallization peak was absent. Likewise, region B showed two distinct melting peaks, whereas in the DSC experiment only a single peak was observed.

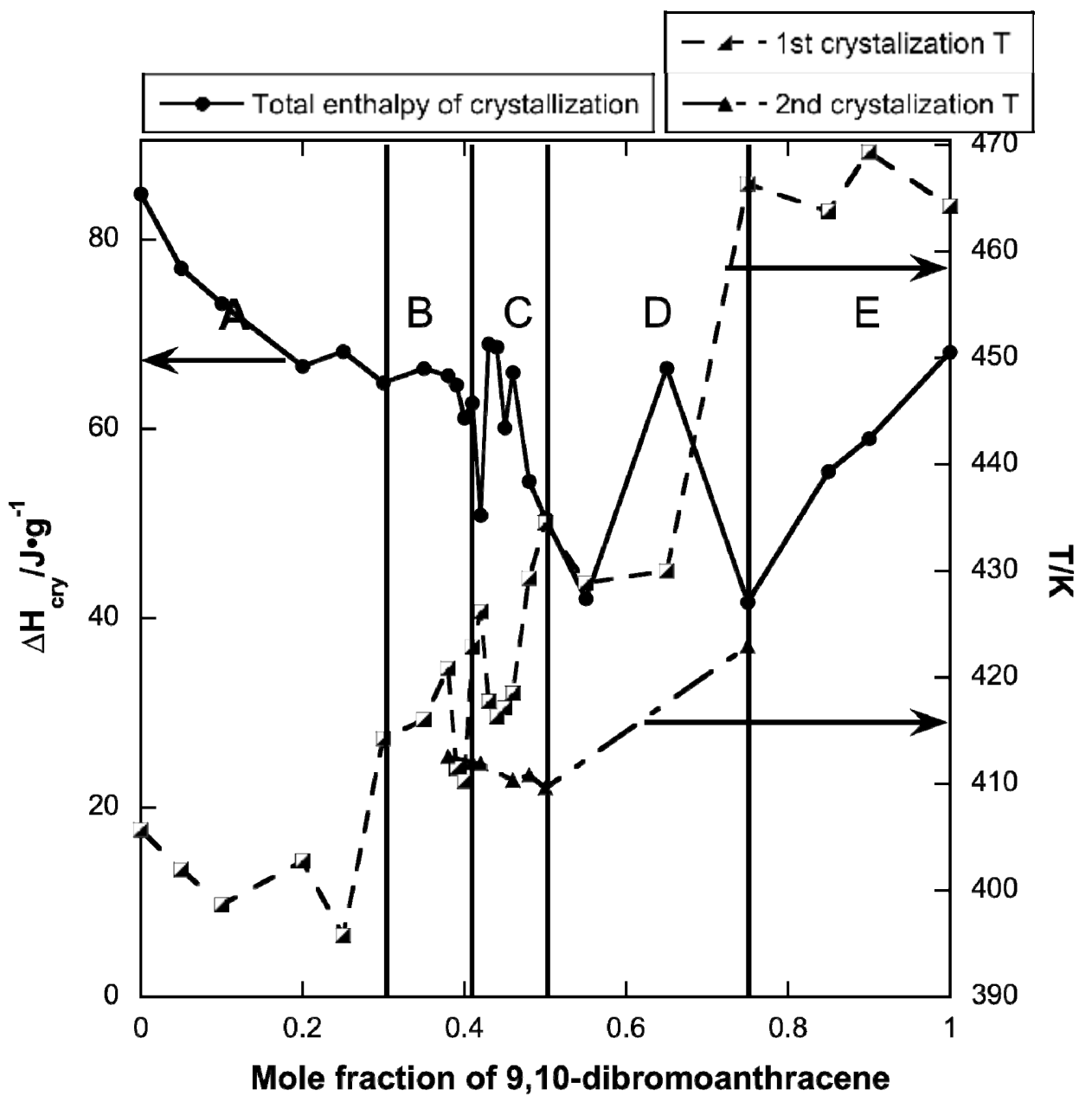

Fig. 10. Crystallization temperature and total enthalpy of crystallization of pyrene (1) +9,10dibromoanthracene (2) mixtures. $1^{\text {st }}$ crystallization temperature is the higher temperature peak in the DSC cooling scan, and $2^{\text {nd }}$ crystallization temperature is the lower temperature peak in the DSC cooling scan (Fu et al., 2010). 
Since the enthalpies of crystallization of the mixtures with 9,10-dibromoanthracene mole fractions of 0.55 and 0.75 are significantly lower than that of other mixtures, these are at a higher energy state and are less stable than other mixtures with nearby compositions. Moreover, the mixture with 0.65 mole fraction of 9,10-dibromoanthracene is in a more stable state than those mixtures with 0.55 and 0.75 mole fraction of 9,10-dibromoanthracene meaning that around a 2:1 molar ratio of 9,10-dibromoanthracene to pyrene, there exists a particular lower energy configuration.

The powder X-ray diffraction method was used to study the crystal structures of the pyrene and 9,10-dibromoanthracene mixtures (see Figure 11). The results are qualitative. For the 9,10-dibromoanthracene rich mixture at the region D-E boundary, at $x_{2}=0.75$ (curve E), the XRD data show a 9,10-dibromoanthracene like microstructure though there are distinct differences from 9,10-dibromoanthracene. The pyrene rich mixture in region $\mathrm{A}$ at $\mathrm{x}_{2}=0.25$ (curve A) has the pyrene like microstructure. However, the mixture at $x_{2}=0.65$ (curve D) reflects neither pyrene nor 9,10-dibromoanthracene like microstructure, and in fact is amorphous.

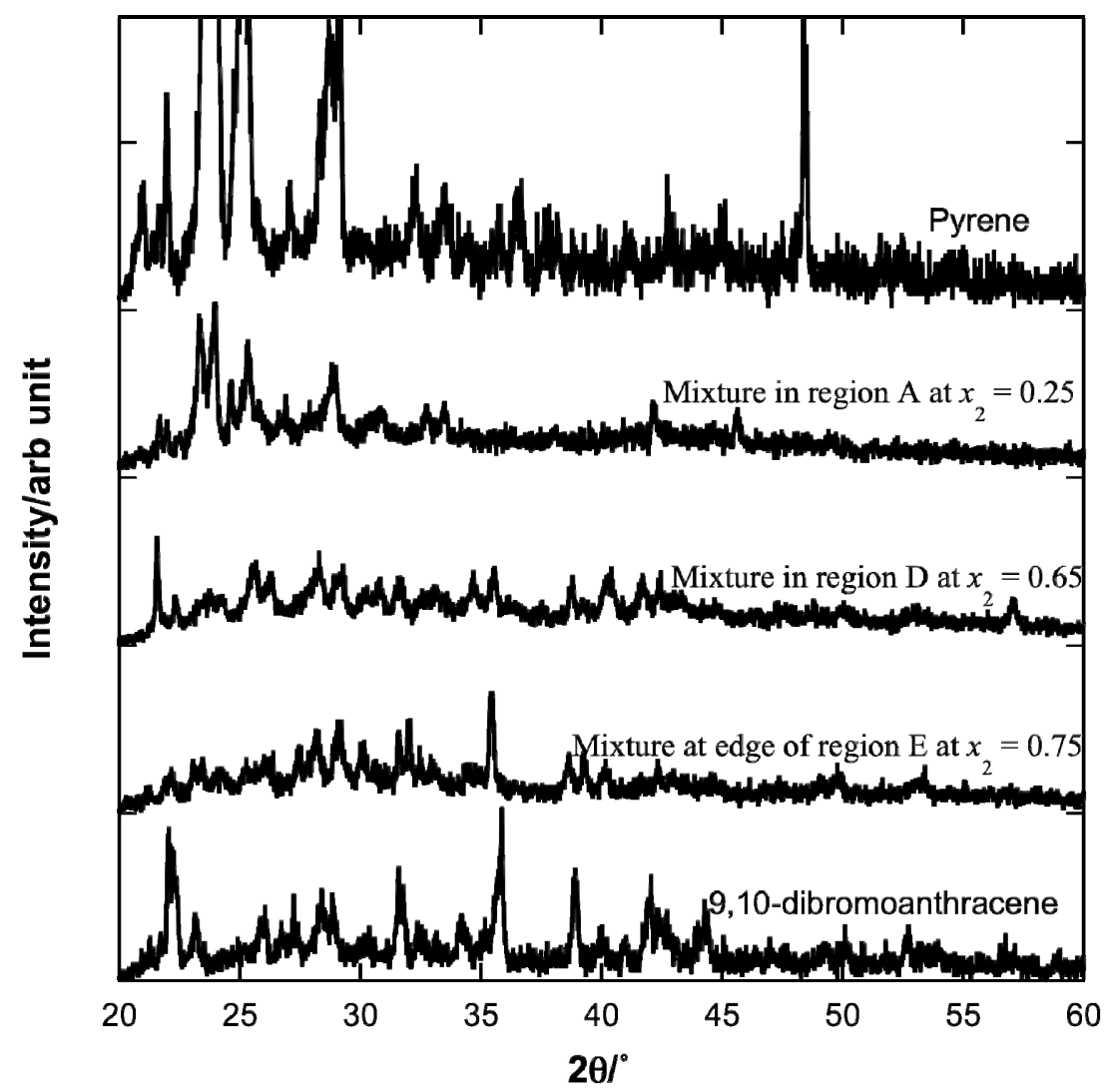

Fig. 11. X-ray diffraction patters of pure components and mixtures of pyrene $(1)+9,10-$ dibromoanthracene(2) (Fu et al., 2010). 


\subsection{Anthracene + 2-bromoanthracene system}

The influence of bromine substitution on thermochemical properties of $\mathrm{PAH}$ mixture systems was further investigated by studying the anthracene (1) + 2-bromoanthracene (2) system. The crystal structure is changed by addition one bromine atom on the aromatic ring. Moreover, the surface area and volume of 2-bromoanthracene is about $10 \%$ bigger than those of anthracene.

The solid-liquid equilibrium diagram of anthracene (1) + 2-bromoanthracene (2) system is shown in Figure 12. The diagram suggests the non-ideality of the anthracene $+2-$ bromoanthracene system. The melting temperature range (thaw to completion) of these mixtures at any given composition is observed to be $1.1-2.6 \mathrm{~K}$. The reported solid-liquid equilibrium melting temperature is here taken as the thaw temperature, in Figure 12. The lowest solid-liquid equilibrium temperature for the system is $477.65 \mathrm{~K}$ at $x_{1}=0.74$, and the melting temperature range of this mixture is $1.8 \mathrm{~K}$.

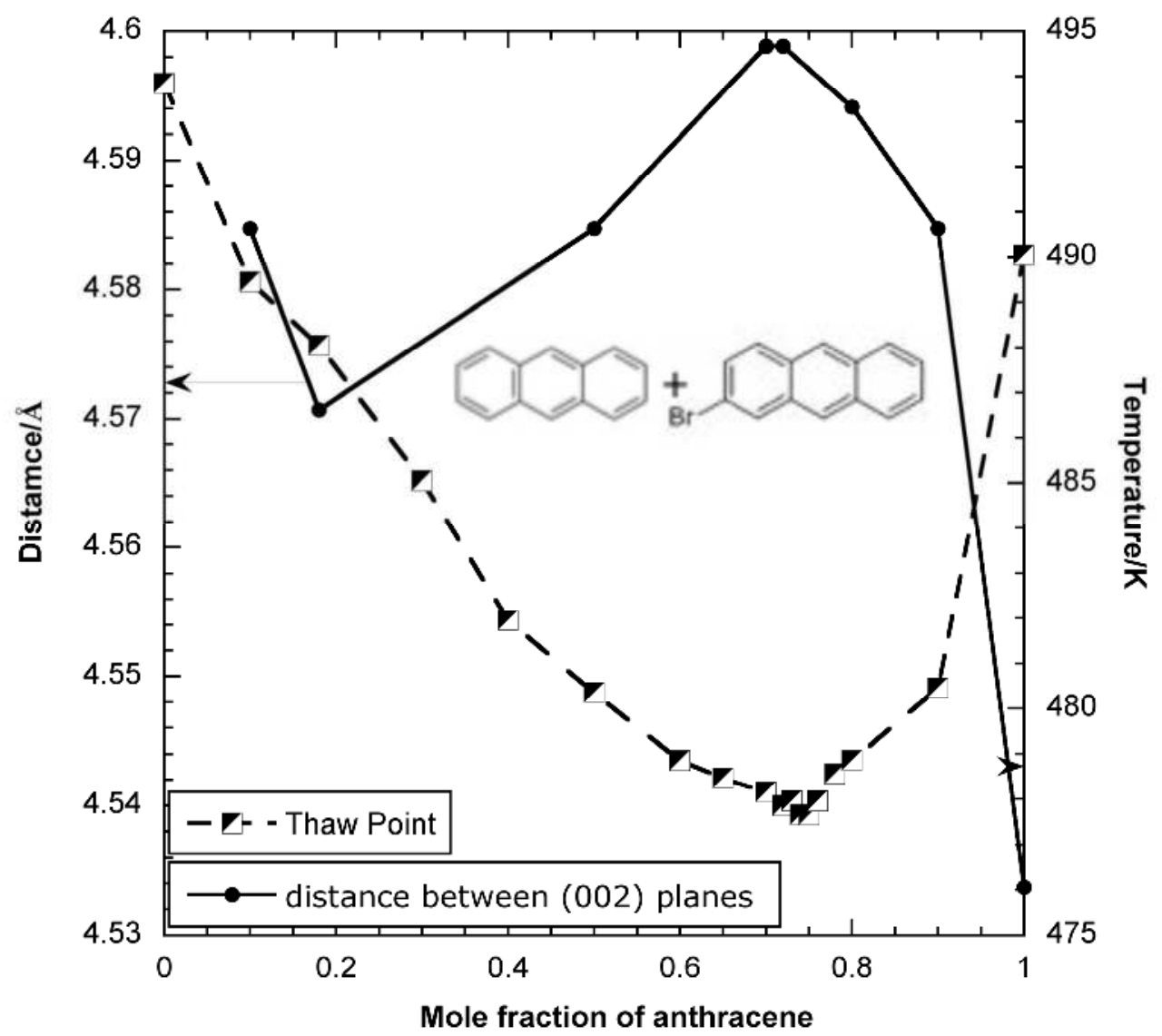

Fig. 12. Phase diagram and distance between (002) planes of anthracene (1) + 2bromoanthracene (2) system. 
The powder X-ray diffraction method was also used to study the crystal structures of pure anthracene, 2-bromoanthracene and their mixtures (see Figure 13). The lattice structure of anthracene crystals is monoclinic with $a=8.44 \AA, b=5.99 \AA, c=11.11 \AA$, $\beta=125.4^{\circ}$ (Jo et al., 2006). The strong diffraction peak at $19.58^{\circ}$ in pure anthracene corresponds to the (002) plane, and the spacing between the 002 planes is $4.53 \AA$. With the increase of the mole fraction of 2-bromoanthracene, $x_{2}$, in the mixture, the (002) plane spacing starts to shift to lower values. Moreover, a new diffraction peak occurs near $2 \theta=17^{\circ}$ with increasing $x_{2}$ in the mixture. This indicates that new mixture crystals are formed. The new peak appears at $2 \theta=$ $16.38^{\circ}$ when $x_{1}=0.70$ roughly corresponding to the lowest solid-liquid equilibrium melting point. With increase of $x_{1}$, the peak position increases from $16.38^{\circ}$ to $17.06^{\circ}$ and disappears in pure anthracene. The diffraction data for mixtures with $x_{1}=0.50$ and 0.10 indicate relatively amorphous structures.

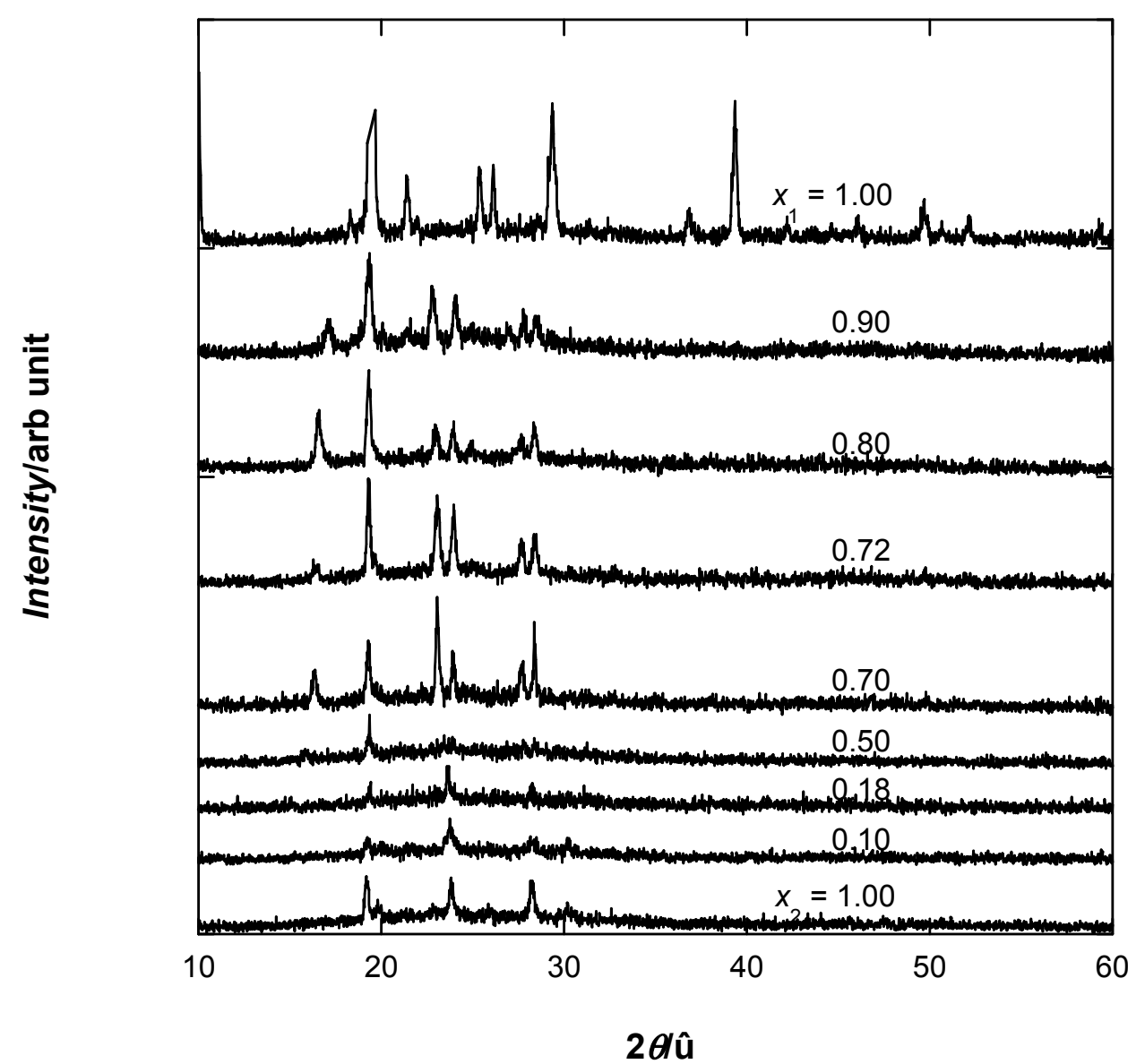

Fig. 13. X-ray diffraction patters of pure components and mixtures of anthracene (1) + 2-bromoanthracene(2). 
The distance between 002 planes in the pure anthracene, pure 2-bromoanthracene and mixtures can be calculated by Bragg's law

$$
n \lambda=2 d \sin \theta
$$

where $n$ is an integer, $\lambda$ is the wavelength of the incident wave, $d$ is the spacing between the planes in the atomic lattice, and $\theta$ is the angle between the incident ray and the scattering planes.

Figure 12 also shows changes of the distance between 002 planes in this system, which demonstrates that the spacings between 002 planes are stretched by adding 2bromoanthracene into anthracene. The distance between 002 planes reaches a maximum when the mixture is near the lowest melting solid-liquid equilibrium point, which is in good agreement with the thermodynamic data in Figure 12, indicating the formation of the least stable solid state near the lowest solid-liquid equilibrium point. Interestingly, the mixture at $x_{1}=0.18$ gives a local minimum in the (002) plane spacing.

\section{Conclusions}

The phase behaviors of binary PAH-containing mixtures are complicated. Most of these mixture systems are eutectic systems, which have a behavior like the anthracene + pyrene system. Fewer binary PAH-containing mixtures can form monotectic and solid solution systems, such as succinonitrile + pyrene system and phenanthrene + anthracene system.

The phase behaviors of binary PAC mixtures are complicated and non-ideal. Mixtures with large PAHs, such as benzo[a]pyrene, can exhibit a gap between the thaw curve and liquidus curve. Halogen substitution (bromine substitution) also has significant effect on the thermochemical behaviors of binary PAC mixtures. Bromine substitution on anthracene results in non-ideal phase behavior in pyrene $+9,10$-dibromoanthracene and anthracene +2 bromoanthracene systems.

\section{Acknowledgement}

This project was supported by Grant Number P42 ES013660 from the National Institute of Environmental Health Sciences (NIEHS)/NIH, and the contents are solely the responsibility of the authors and do not necessarily represent the official views of the NIEHS/NIH.

\section{References}

Bender, R., Bieling, V., Maurer, G., 1983. The vapour pressures of solids: anthracene, hydroquinone, and resorcinol. The Journal of Chemical Thermodynamics 15, 585594.

Burks, G.A., Harmon, T.C., 2001. Volatilization of solid-phase polycyclic aromatic hydrocarbons from model mixtures and lampblack-contaminated soils. J Chem Eng Data 46, 944-949. 
Chickos, J.S., Acree, W.E., 1999. Estimating solid-liquid phase change enthalpies and entropies. J Phys Chem Ref Data 28, 1535-1673.

De Kruif, C., 1980. Enthalpies of sublimation and vapor-pressure of 11 polycyclichydrocarbons. J Chem Thermodyn 12, 243-248.

Fu, J., Rice, J.W., Suuberg, E.M., 2010. Phase behavior and vapor pressures of the pyrene + 9,10-dibromoanthracene system. Fluid Phase Equilibr 298, 219-224.

Goldfarb, J.L., Suuberg, E.M., 2008a. The effect of halogen hetero-atoms on the vapor pressures and thermodynamics of polycyclic aromatic compounds measured via the Knudsen effusion technique. J Chem Thermodyn 40, 460-466.

Goldfarb, J.L., Suuberg, E.M., 2008b. Vapor pressures and enthalpies of sublimation of ten polycyclic aromatic hydrocarbons determined via the Knudsen effusion method. J Chem Eng Data 53, 670-676.

Goldfarb, J.L., Suuberg, E.M., 2008c. Vapor pressures and thermodynamics of oxygencontaining polycyclic aromatic hydrocarbons measured using Knudsen effusion. Environ Toxicol Chem 27, 1244-1249.

Gupta, R.K., Singh, R.A., 2004. Thermochemical and microstructural studies on binary organic eutectics and complexes. Journal of Crystal Growth 267, 340-347.

Haglund, P., Alsberg, T., Bergman, A., Jansson, B., 1987. Analysis of Halogenated Polycyclic Aromatic-Hydrocarbons in Urban Air, Snow and Automobile Exhaust. Chemosphere 16, 2441-2450.

Hansen, P.C., Eckert, C.A., 1986. An Improved Transpiration Method for the Measurement of Very Low Vapor-Pressures. J Chem Eng Data 31, 1-3.

Hinckley, D.A., Bidleman, T.F., Foreman, W.T., Tuschall, J.R., 1990. Determination of VaporPressures for Nonpolar and Semipolar Organic-Compounds from GasChromatographic Retention Data. J Chem Eng Data 35, 232-237.

Horii, Y., Khim, J.S., Higley, E.B., Giesy, J.P., Ohura, T., Kannan, K., 2009. Relative Potencies of Individual Chlorinated and Brominated Polycyclic Aromatic Hydrocarbons for Induction of Aryl Hydrocarbon Receptor-Mediated Responses. Environ Sci Technol 43, 2159-2165.

Horii, Y., Ok, G., Ohura, T., Kannan, K., 2008. Occurrence and profiles of chlorinated and brominated polycyclic aromatic hydrocarbons in waste incinerators. Environ Sci Technol 42, 1904-1909.

Ishaq, R., Naf, C., Zebuhr, Y., Broman, D., Jarnberg, U., 2003. PCBs, PCNs, PCDD/Fs, PAHs and Cl-PAHs in air and water particulate samples - patterns and variations. Chemosphere 50, 1131-1150.

Jo, S., Yoshikawa, H., Fujii, A., Takenaga, M., 2006. Surface morphologies of anthracene single crystals grown from vapor phase. Appl Surf Sci 252, 3514-3519.

Kitazawa, A., Amagai, T., Ohura, T., 2006. Temporal trends and relationships of particulate chlorinated polycyclic aromatic hydrocarbons and their parent compounds in urban air. Environ Sci Technol 40, 4592-4598.

Koistinen, J., Paasivirta, J., Nevalainen, T., Lahtipera, M., 1994a. Chlorinated Fluorenes and Alkylfluorenes in Bleached Kraft Pulp and Pulp-Mill Discharges. Chemosphere 28, 2139-2150. 
Koistinen, J., Paasivirta, J., Nevalainen, T., Lahtipera, M., 1994b. Chlorophenanthrenes, Alkylchlorophenanthrenes and Alkylchloronaphthalenes in Kraft Pulp-Mill Products and Discharges. Chemosphere 28, 1261-1277.

Lei, Y.D., Chankalal, R., Chan, A., Wania, F., 2002. Supercooled liquid vapor pressures of the polycyclic aromatic hydrocarbons. J Chem Eng Data 47, 801-806.

Luthy, R.G., Dzombak, D.A., Peters, C.A., Roy, S.B., Ramaswami, A., Nakles, D.V., Nott, B.R., 1994. Remediating Tar-Contaminated Soils at Manufactured-Gas Plant Sites. Environ Sci Technol 28, A266-A276.

Ma, Y.G., Lei, Y.D., Xiao, H., Wania, F., Wang, W.H., 2010. Critical Review and Recommended Values for the Physical-Chemical Property Data of 15 Polycyclic Aromatic Hydrocarbons at 25 degrees C. J Chem Eng Data 55, 819-825.

Mackay, D., Bobra, A., Chan, D.W., Shiu, W.Y., 1982. Vapor-Pressure Correlations for LowVolatility Environmental Chemicals. Environ Sci Technol 16, 645-649.

Mackay, D., Shiu, W.Y., Ma, K.-C., Lee, S.C., 2006. Physical-Chemical Properties and Environmental Fate for Organic Chemicals. CRC Press.

Matsuoka, M.G., J. (ed); Davey, R.J (ed); Jones A. (ed), 1991. Advances in Industrial Crystallization. Butterworth-Heinemann, Oxford.

Murray, J.J., Pottie, R.F., 1974. The Vapor Pressures and Enthalpies of Sublimation of Five Polycyclic Aromatic Hydrocarbons. Canadian Journal of Chemistry 52, 557-563.

Nass, K., Lenoir, D., Kettrup, A., 1995. Calculation of the Thermodynamic Properties of Polycyclic Aromatic-Hydrocarbons by an Incremental Procedure. Angew Chem Int Edit 34, 1735-1736.

Ni, H.G., Zeng, H., Tao, S., Zeng, E.Y., 2010. Environmental and Human Exposure to Persistent Halogenated Compounds Derived from E-Waste in China. Environ Toxicol Chem 29, 1237-1247.

Nilsson, U.L., Ostman, C.E., 1993. Chlorinated Polycyclic Aromatic-Hydrocarbons Method of Analysis and Their Occurrence in Urban Air. Environ Sci Technol 27, 1826-1831.

Odabasi, M., Cetin, E., Sofuoglu, A., 2006. Determination of octanol-air partition coefficients and supercooled liquid vapor pressures of PAHs as a function of temperature: Application to gas-particle partitioning in an urban atmosphere. Atmos Environ 40, 6615-6625.

Ohura, T., Morita, M., Kuruto-Niwa, R., Amagai, T., Sakakibara, H., Shimoi, K., 2010. Differential Action of Chlorinated Polycyclic Aromatic Hydrocarbons on Aryl Hydrocarbon Receptor-Mediated Signaling in Breast Cancer Cells. Environ Toxicol 25, 180-187.

Ohura, T., Sawada, K.I., Amagai, T., Shinomiya, M., 2009. Discovery of Novel Halogenated Polycyclic Aromatic Hydrocarbons in Urban Particulate Matters: Occurrence, Photostability, and AhR Activity. Environ Sci Technol 43, 2269-2275.

Oja, V., Suuberg, E.M., 1997. Development of a nonisothermal Knudsen effusion method and application to PAH and cellulose tar vapor pressure measurement. Anal Chem $69,4619-4626$. 
Pounder, F.E., Masson, I., 1934. Thermal analysis, and its application to dinitrobenzenes. J. Chem. Soc., 1357-1360.

Rai, U.S., Pandey, P., 2002. Crystallization behaviour of metal-nonmetal monotectic alloys; Succinonitrile-pyrene system. Progress in Crystal Growth and Characterization of Materials 45, 59-64.

Rastogi, R.P., Bassi, P.S., 1964. Mechanism of Eutectic Crystallization. The Journal of Physical Chemistry 68, 2398-2406.

Rastogi, R.P., Rama Varma, K.T., 1956. Solid-liquid equilibria in solutions of nonelectrolytes. Journal of the Chemical Society, 2097-2101.

Rice, J.W., Fu, J., Suuberg, E.M., 2010. Anthracene + Pyrene Solid Mixtures: Eutectic and Azeotropic Character. Journal of Chemical \& Engineering Data, doi: 10.1021/je100208e.

Rice, J.W., Suuberg, E.M., 2010. Thermodynamic study of (anthracene + benzo[a]pyrene) solid mixtures. The Journal of Chemical Thermodynamics 42, 1356-1360.

Ruzicka, K., Mokbel, I., Majer, V., Ruzicka, V., Jose, J., Zabransky, M., 1998. Description of vapour-liquid and vapour-solid equilibria for a group of polycondensed compounds of petroleum interest. Fluid Phase Equilibria 148, 107-137.

Sato, N., Inomata, H., Arai, K., Saito, S., 1986. Measurement of Vapor-Pressures for CoalRelated Aromatic-Compounds by Gas Saturation Method. J Chem Eng Jpn 19, 145147.

Shiraishi, H., Pilkington, N.H., Otsuki, A., Fuwa, K., 1985. Occurrence of Chlorinated Polynuclear Aromatic-Hydrocarbons in Tap Water. Environ Sci Technol 19, 585590.

Shiu, W.Y., Ma, K.C., 2000. Temperature dependence of physical-chemical properties of selected chemicals of environmental interest. I. Mononuclear and polynuclear aromatic hydrocarbons. J Phys Chem Ref Data 29, 41-130.

Singh, N.B., Rai, U.S., Singh, O.P., 1985. Chemistry of eutectic and monotectic; phenanthrene-succinonitrile system. Journal of Crystal Growth 71, 353-360.

Singh, N.B., Srivastava, A., Singh, N.P., Gupta, A., 2007. Molecular interaction between naphthalene and 2,4-dinitrophenol in solid state. Molecular Crystals and Liquid Crystals 474, 43-+.

Singh, N.B., Srivastava, M.A., Singh, N.P., 2001. Solid-liquid equilibrium for 2,4dinitrophenol plus naphthalene. J Chem Eng Data 46, 47-50.

Sonnefeld, W.J., Zoller, W.H., May, W.E., 1983. Dynamic Coupled-Column LiquidChromatographic Determination of Ambient-Temperature Vapor-Pressures of Polynuclear Aromatic-Hydrocarbons. Anal Chem 55, 275-280.

Sun, C.G., Snape, C.E., McRae, C., Fallick, A.E., 2003. Resolving coal and petroleum-derived polycyclic aromatic hydrocarbons (PAHs) in some contaminated land samples using compound-specific stable carbon isotope ratio measurements in conjunction with molecular fingerprints. Fuel 82, 2017-2023.

Szczepanik, Richard, Skalmowski, Wlodzimierz, 1963. Effects of crystal growth and volatilization of tar components on the aging of prepared tar. III. Solid-liquid phase relationship of the components of raw coal tar and prepared road tar. Bitumen, Teere, Asphalte, Peche 14, 506,508-512,514. 
Szczepanik, Ryszard, 1963. Two- and multicomponent, solid-liquid systems formed by aromatic hydrocarbons, anthraquinone, and coal-tar fractions. Chem. Stosowana Ser. A 7, 621-660.

Wakayama, N., Inokuchi, H., 1967. Heats of sublimation of polycyclic aromatic hydrocarbons and their molecular packings. 40, 2267-2271. 


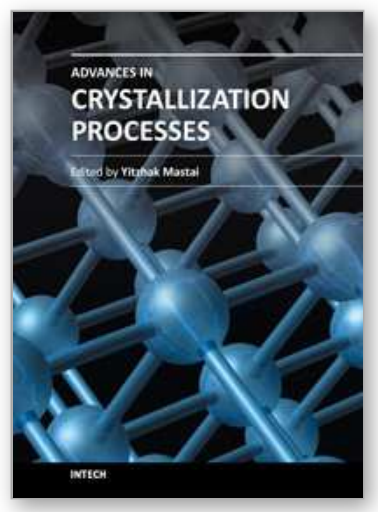

\section{Advances in Crystallization Processes}

Edited by Dr. Yitzhak Mastai

ISBN 978-953-51-0581-7

Hard cover, 648 pages

Publisher InTech

Published online 27, April, 2012

Published in print edition April, 2012

Crystallization is used at some stage in nearly all process industries as a method of production, purification or recovery of solid materials. In recent years, a number of new applications have also come to rely on crystallization processes such as the crystallization of nano and amorphous materials. The articles for this book have been contributed by the most respected researchers in this area and cover the frontier areas of research and developments in crystallization processes. Divided into five parts this book provides the latest research developments in many aspects of crystallization including: chiral crystallization, crystallization of nanomaterials and the crystallization of amorphous and glassy materials. This book is of interest to both fundamental research and also to practicing scientists and will prove invaluable to all chemical engineers and industrial chemists in the process industries as well as crystallization workers and students in industry and academia.

\section{How to reference}

In order to correctly reference this scholarly work, feel free to copy and paste the following:

Jinxia Fu, James W. Rice and Eric M. Suuberg (2012). Phase Behavior and Crystal Structure of Binary Polycyclic Aromatic Compound Mixtures, Advances in Crystallization Processes, Dr. Yitzhak Mastai (Ed.), ISBN: 978-953-51-0581-7, InTech, Available from: http://www.intechopen.com/books/advances-incrystallization-processes/phase-behavior-and-crystal-structure-of-polycyclic-aromatic-compound-mixtures

\section{INTECH}

open science | open minds

\section{InTech Europe}

University Campus STeP Ri

Slavka Krautzeka 83/A

51000 Rijeka, Croatia

Phone: +385 (51) 770447

Fax: +385 (51) 686166

www.intechopen.com

\section{InTech China}

Unit 405, Office Block, Hotel Equatorial Shanghai

No.65, Yan An Road (West), Shanghai, 200040, China 中国上海市延安西路65号上海国际贵都大饭店办公楼 405 单元 Phone: +86-21-62489820

Fax: $+86-21-62489821$ 
(C) 2012 The Author(s). Licensee IntechOpen. This is an open access article distributed under the terms of the Creative Commons Attribution 3.0 License, which permits unrestricted use, distribution, and reproduction in any medium, provided the original work is properly cited. 